\title{
FRICTION SURFACING OF STAINLESS STEEL ON LOW CARBON STEEL FOR CORROSION RESISTANCE APPLICATION-AN EXPERIMENTAL APPROACH
}

\author{
BDY SUNIL ${ }^{1}$, C. LABESH KUMAR ${ }^{2}, \&$ S. MADHU ${ }^{3}$ \\ ${ }^{1,2}$ Assistant Professor, Department of Mechanical Engineering, Institute of \\ Aeronautical Engineering, Hyderabad, Telangana, India \\ ${ }^{3}$ Professor Department of Mechanical Engineering MLR Institute of Technology, Dundigal, Hyderabad, India
}

\begin{abstract}
The friction surfacing is one of the friction welding processes, used for deposition of desired material on substrate. These deposits being of solid phase bonding, no external heat source is required and it is very much suitable for critical applications such as wear resistance, corrosion resistance and challenging joining applications.

In the present work, the parameters for the optimal performance of the machining operation for acquiring a sound deposit were calculated for Stainless Steel mechtrode and Low Carbon Steel substrate combination. Friction surfacing was carried out on a friction surfacing/ stir welding machine. The deposits acquired were tested for the shear strength of the bond, tensile strength of the bond, by preparing the samples from the acquired product. Width of the deposit, height of the deposit, and surface roughness of the deposit were measured by using the respective instruments. The observed values gathered after the testing were verified with the regression equations and the results were analyzed, for the optimal process parameters for acquiring a sound bonding, between the parent materials of Stainless Steel mechtrode and Low Carbon Steel substrate. Based on the analysis of the characteristics of the bond (width, height, surface roughness, shear strength, and tensile strength), by varying the process parameters (frictional pressure, speed and transverse speed) the deposits are found to be fruitfully sound and the aim of the work is fulfilled.
\end{abstract}

KEYWORDS: Friction Welding, Friction Surfacing, Low Carbon and Stainless Steel

Received: Jul 29, 2017; Accepted: Aug 17, 2017; Published: Sep 02, 2017; Paper Id.: IJMPERDOCT201714

\section{INTRODUCTION}

Surface engineering has gained wide importance in view of certain advantages like wear and corrosion resistance, aesthetic appearance to the surfaces, in-service performance, working life-times, friction energy losses, act as a diffusion barrier, provide thermal insulation, exclude certain wavelengths of radiation, promote radiation electronic interactions, electrically insulate etc. Friction surfacing technique is an important form of surface engineering. Friction energy has long been used as a means of providing the heat needed to weld a variety of materials. The method has gained important position, worldwide as a commercial joining process in industries as diverse as aerospace, automotive and offshore oil exploration. The solid phase process of friction welding has been further modified, to allow the deposition of surface layers onto a substrate. This method of metal transfer is now known as friction surfacing.

Friction surfacing, which is related to friction welding, utilizes the frictional energy dissipated during operation and generates a layer of plasticized metal, the layer of plasticized metal being deposited as a coating without the need for external heat source. In this process, the consumable rod of coating metal moves, relative to 
the substrate in linear direction whilst rotating relative to the substrate under the action of external load.

Klopstock and Neelands first patented the friction surfacing as a metal coating process in 1941. Afterwards, i.e., in early 1980's friction surfacing was developed as an industrial process. Several other investigators have also worked in the area. This process has been used for obtaining various dissimilar metal coatings, such as tool steel coatings on mild steel or stainless steel on mild steel. Dissimilar metal coatings are made possible by the generation of high contact stress and intimate contact, between the coating material and substrate, which initiates solid-state adhesion between the coating and the substrate. Strong bonding is achieved between the coating and the substrate, in the friction surfacing process if a high contact pressure is used, which requires expensive machinery.

The process of friction surfacing is schematically depicted in the following figure:

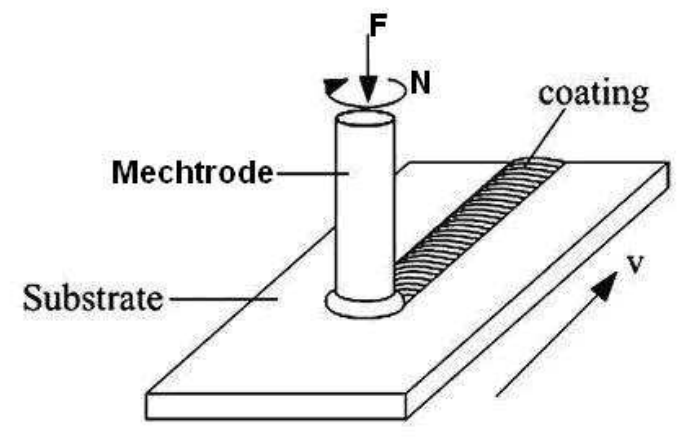

Figure 1: Principle of Friction Surfacing

\section{EXPERIMENT SETUP}

The experimental work has been carried out sequentially, by knowing the correct procedure for obtaining the friction surfaced deposit, by knowing the parameters that effects the deposit, by calculating the correct process parameters for obtaining good deposit, and conducting the experiment on the materials with the obtained parameters. The experimental work has been conducted as follows:

\section{Selection of Process Parameters}

The correct selection of parameters for the process plays a crucial role for the feasible and strong bonding between the materials being used.

\section{Parameters Involved}

The process parameters involved in this friction surfacing technique are

- $\quad$ Friction force $(\mathrm{F})$

- $\quad$ Speed of the mechatrode $(\mathrm{N})$

- $\quad$ Travel speed of substrate $(\mathrm{S})$

Friction Force: This Friction Force depends on the forging pressure, which is the material property having the forging strength at forging temperature.

Speed: Selection of speed depends on the required quantity of heat generated when forging pressure is applied in the process. 
Feed: Selection of feed depends on the maximum thickness of the material to be deposited in the process.

For the selection of process parameters the following points are considered

The level of process parameters depends on the metallurgical considerations like formation of intermetallic compounds due to diffusion phenomena between consumable rod and substrate.

- The physical properties like thermal conductivity and specific heat also influence the level of parameters.

- The torque-time characteristics are important for the quantum of heat generated.

- During the initial stages of the process, there is an application of force on the rotating consumable rod which is made to be in metallic contact with the substrate. This causes peak torque in a very short time.

The selection of parameters depends mainly on the metallurgical properties of the materials being used. The key point of this process is the generation of heat because of friction caused by rubbing action. The temperature of consumable end, which is in contact with the substrate, is increased to the forging temperature of the consumable material, to be reached within 5-10 seconds, depending on the material.

By taking into consideration the forging temperature, the heat generated can be calculated from the fundamental equation as, $\mathbf{Q}=\mathbf{m} \mathbf{s} \Delta \mathbf{T}$

Where, $\mathrm{m}=$ mass of the material being heated (in $\mathrm{Kg}$ )

$\mathrm{s}=$ specific heat $($ in $\mathrm{KJ})$

$\Delta \mathrm{T}=($ forging temperature - room temperature $)$

Hence, for a given diameter of the mechatrode rod,

$=>\mathbf{Q}=\underline{\mathbf{\rho} \times \mathbf{A} \times \mathbf{h} \times \mathbf{S} \times \Delta \mathbf{T}}$

\section{0}

Where,

$\rho=$ density of the material in $\mathrm{Kg} / \mathrm{m}^{3}$

$\mathrm{A}=$ circular area of the mechatrode in contact with substrate (in $\mathrm{mm}^{2}$ )

$\mathrm{h}=$ expected height of the mechatrode to get plastic state (in $\mathrm{mm}$ )

The quantity of heat generated in the process is related to the power consumed in friction surfacing and it can be determined by,

\section{$\mathbf{P}=\underline{2 \text { II N T }}$}

\section{0}

And thus the horse power required for the process can be known.

The amount of power consumed in friction surfacing is utilized to raise the temperature of the mechatrode rod and substrate. 
The power consumed, $\mathrm{P}=\underline{2 \Pi \mathrm{N} \mathrm{T}}$

60 [max. heat is generated at $2 / 3^{\text {rd }}$ radius]

$=\underline{2 \Pi \mathrm{N}(2 / 3 \mu \mathrm{FR})}$

$60 \times 1000$

[For converting Press. into N/mm2]

$=\underline{2 \Pi \mathrm{N} 2 / 3 \mu(\mathrm{PA}) \mathrm{R} \times 9.8}$

$60 \times 1000$

\section{$3 \underline{\mu A R}[\mathbf{P} \times \mathbf{N}]$}

1000

Where, ' $\mathrm{P}$ ' is in $\mathrm{kg} / \mathrm{mm}^{2}$

' $A$ ' is in $\mathrm{mm}^{2}$

' $\mathrm{R}$ ' is in $\mathrm{mm}$

Now, from equations $1 \& 2$, relating power with heat generated, $\mathrm{Q}=\mathrm{P}$

$\underline{\rho \times \mathrm{A} \times \mathrm{h} \times \mathrm{s} \times \Delta \mathrm{T}}=2 / 3 \underline{\mu \mathrm{AR}}[\mathrm{P} \times \mathrm{N}]$

10000001000

$=>[\mathrm{P} \times \mathrm{N}]=[\underline{3 \times(\rho s \Delta \mathbf{T})}] \underline{\mathrm{h}}$

$[2000 \times(\mu)] \mathrm{R}$

$=>[\mathrm{P} \times \mathrm{N}]=\mathrm{C} \times \mathrm{h} / \mathrm{R}$

Where ' $C$ ' is a constant for a given material.

Hence for a given material, the above relation can be depicted as,

$\underline{\mathbf{P}}_{1} \underline{\mathbf{N}}_{1} \underline{\mathbf{R}}_{1}=\underline{\mathbf{P}}_{2} \underline{\mathbf{N}}_{2} \underline{\mathbf{R}}_{2}$

$\begin{array}{ll}\mathbf{h}_{1} & \mathbf{h}_{2}\end{array}$

For Stainless Steel material,

Density $=7850 \mathrm{Kg} / \mathrm{m}^{3}$

Specific Heat $=0.502 \mathrm{KJ} /{ }^{\circ} \mathrm{C}$

$\Delta \mathrm{T}=1263$

$\mu=0.8$

Substituting the above values for determining the value of $\mathrm{C}$, the equation 'A' for Stainless Steel becomes, $\mathrm{P} \times \mathrm{N}=(9295) \mathrm{h} / \mathrm{R}$ 
Thus the height of the material to get plastic state can be calculated for a given diameter of the mechtrode rod.

Determining thickness of coating

The volume of material heated $=\Pi / 4 \times \mathrm{d}^{2} \times \mathrm{h}$

Where, $\mathrm{h}=$ height of the material heated at forging temperature.

$\mathrm{d}=$ diameter of mechtrode rod.

The volume of material deposited $=\mathrm{d} \times \mathrm{V}_{\mathrm{x}} \times \mathrm{t}$

where, $\mathrm{d}=$ width of the weld (same as diameter of the mechtrode)

$\mathrm{V}_{\mathrm{x}}=$ distance traveled by substrate in $\mathrm{X}$-direction

$\mathrm{t}=$ thickness of the weld

Percentage of the material deposited

$=\underline{\mathrm{d} \times \mathrm{V}_{x}} \underline{x} \times 100$

$\Pi / 4 \times d^{2} \times h$

Which is equal to $4.5 \%$ of the material being changed to plastic state.

Therefore, $\underline{\mathrm{d} \times \mathrm{V}_{x}} \underline{\underline{x t}}=0.045$

$$
\Pi / 4 \times \mathrm{d}^{2} \times \mathrm{h}
$$

For the $15 \mathrm{~mm}$ diameter of the Stainless Steel rod used, the thickness of the coating is go by,

$\mathrm{t}=0.52 \times \mathrm{h} / \mathrm{V}_{\mathrm{x}}$

It was found from calculations that, in friction surfacing nearly four percent stainless steel, which was heated to forging temperature at initial stage was deposited over the low carbon steel. From above guidelines, it is possible to keep the range of the parameters, required for surfacing. Hence, it is necessary to determine the optimum parameters for any size of the consumable rod, due to interaction effects the final result of deposit varies. By designing a method for determining optimum conditions, for achieving quality deposits by an approach, which minimizes number of trials compared, by varying one parameter at a time and keeping others constant.

The Stainless Steel rod in the annealed condition is expected to have $60 \mathrm{~kg} / \mathrm{mm} 2$ ultimate tensile strength, the guidelines for selection of parameters are (at maximum levels) for $15 \mathrm{~mm}$ diameter consumable

Friction pressures $12 \mathrm{Kg} / \mathrm{mm}^{2}$

Surface speed $2000 \mathrm{rpm}$.

Transverse speed $1-2 \mathrm{~mm} / \mathrm{sec}$

By using above guidelines, the following process parameters are selected for stainless steel mechatrode and Low carbon steel substrate, and after doing calculations for the thickness/height of the deposit, that could be got using the respective parameters the values are tabulated and shown in following table: 
Table 1: Confirmed Process Parameters for different Treatment Combinations

\begin{tabular}{|c|c|c|c|c|}
\hline & \multicolumn{3}{|c|}{ Process Parameters } & \multirow[b]{2}{*}{$\begin{array}{l}\text { Theoretical } \\
\text { Height of the Deposit } \\
\text { (mm) }\end{array}$} \\
\hline & $\begin{array}{c}\text { Friction } \\
\text { Force } \\
\left(\mathrm{Kg} / \mathbf{m m}^{2} / \mathrm{KN}\right)\end{array}$ & $\begin{array}{l}\text { Speed } \\
(\mathbf{r p m})\end{array}$ & $\begin{array}{c}\text { Traverse Speed } \\
\mathrm{mm} / \mathrm{min}\end{array}$ & \\
\hline 1 & $2.96 / 5.12$ & 1500 & 78 & 1.5 \\
\hline 2 & $4.74 / 8.2$ & 1500 & 78 & 2.5 \\
\hline 3 & $2.96 / 5.12$ & 2400 & 78 & 2.2 \\
\hline 4 & $4.74 / 8.2$ & 2400 & 78 & 3.8 \\
\hline 5 & $2.96 / 5.12$ & 1500 & 190.8 & 0.6 \\
\hline 6 & $4.74 / 8.2$ & 1500 & 190.8 & 1.02 \\
\hline 7 & $2.96 / 5.12$ & 2400 & 190.8 & 0.9 \\
\hline 8 & $4.74 / 8.2$ & 2400 & 190.8 & 1.5 \\
\hline
\end{tabular}

Thus, theoretically $4^{\text {th }}$ treatment combination will give good thickness of coating.

\section{PRACTICAL EXPERIMENT}

Practical experiment has been conducted using the materials of stainless steel consumable and low carbon steel substrate. The dimensions of the materials are consumable rod of $15 \mathrm{~mm}$ diameter and 290mm of length, extending from the holder in the friction surfacing machine, and substrate plate of $100 \times 75 \times 12 \mathrm{~mm} 3$ sizes.

The metallographic and hardness tests are performed for mechatrode and substrate before the practical experiment. The micro structure figures of the low carbon steel substrate and stainless steel mechtrode are shown below:

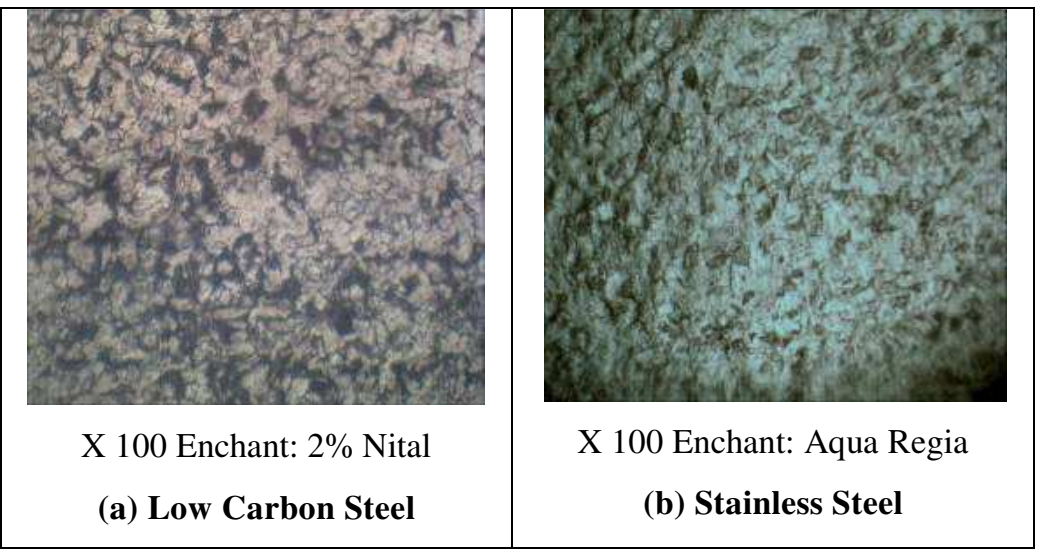

\section{Figure 2}

(Micro structures, Test as per IS: 7739 Part 1)

The mechanical test has been conducted as per standard IS1608, for finding the tensile strength, yield strength, elongation percentage and reduction in area percentage as shown in the following figures:

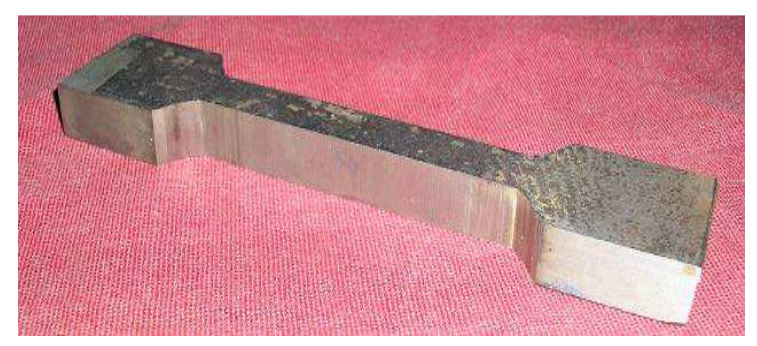


Figure 3: Low Carbon Steel (Substrate)

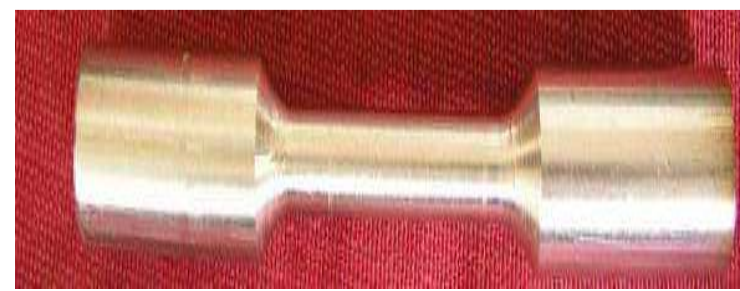

Figure 4: Stainless Steel (Mechtrode)

The chemical composition of the materials is as follows

Table 2

\begin{tabular}{|l|l|}
\hline Stainless Steel 304L & $\begin{array}{c}\text { Low Carbon Steel } \\
\text { IS-2062-Grade B--- }\end{array}$ \\
\hline C-----0.03 & Fe-----99.26 \\
\hline Mn---2.00 & C-----0.22 max \\
\hline Si----1.00 & Mn---1.50 max. \\
\hline Cr----18-20 & S-----0.045 max. \\
\hline Ni-----8-12 & P----0.045 max. \\
\hline P-----0.045 & Si----0.040 max. \\
\hline S-----0.03 & \\
\hline
\end{tabular}

Hardness-261

Tensile strength $\left(\mathrm{N} / \mathrm{mm}^{2}\right)-515$

Yield strength-205

$\%$ of elongation-30

The experiment has been conducted at DMRL, Hyderabad, on a friction surfacing /stir welding machine made by ETA Technology (P) Ltd. Technical specifications of machine are: Motor capacity: 30 KW, Permissible speed range: 1000-2400 RPM, Table Size: 330X450mm.

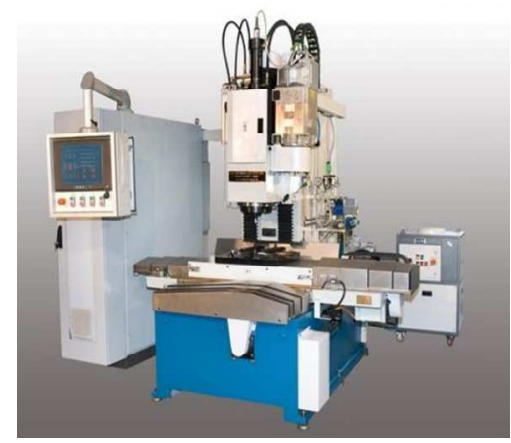

Figure 5: Experimental Procedure/Steps

The experiment was carried out as follows:

- $\quad$ The substrate and mechtrode are cleaned, to remove adhere foreign particles or oil and grease by iso- propane.

- Mark on the substrate having gaps $25 \mathrm{~mm}$ from the reference edge. While depositing sees that, the centre of the deposit is coinciding with this marked line. These gaps are useful in preparation of specimen, for shear and tensile strength testing. 
- Low carbon steel substrate is fitted firmly on the table and stainless steel mechtrode in spindle of friction surfacing machine.

- Check the movement of the table so that obtained deposit should be parallel to the edge of the table.

- Input the calculated/confirmed process parameters which are indicated in table1 and length of the weld into computer of the machine.

- Start the machine, a dwell time of $5 \mathrm{~s}$ is allowed, once the consumable is sufficiently heated to forging temperature (red hot); the traversed feed is automatically switched on.

- The hot consumable material flows plastically over the substrate to form a coating. Since the machine is designed to deposit the consumable material in one direction, after the completion of required length of the weld, the consumable which is fitted in the spindle automatically detach from the substrate.

- At room temperature check the weld for its bond strength by lifting with knife edge tool.

- Measure the length of the consumed rod for that trial.

- $\quad$ The deformed /bulb of the consumable rod is removed by cutting or grinding.

- Repeat the experiment by depositing material with second treatment combination (second set of parameters) on the same substrate with the gap which was marked earlier.

- Complete the remaining six process parameters treatment combinations which are selected from the table on the three substrate plates.

- If the quality of the weld is satisfactory, measure and tabulate the responses in tabular form to determine effect of process parameters.

- After completion of each trial, identify the treatment combination number by marking against the deposit for the reference of further procedure.

Product Obtained

The figures of the coatings obtained are displayed below.

\section{Deposit on I Plate}

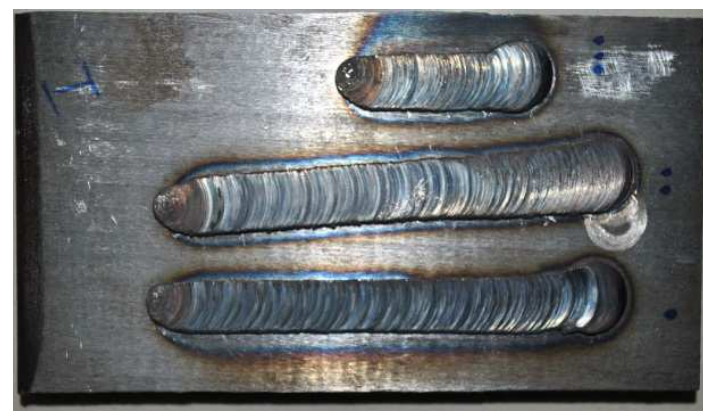

Figure 6 


\section{Deposit on II Plate}

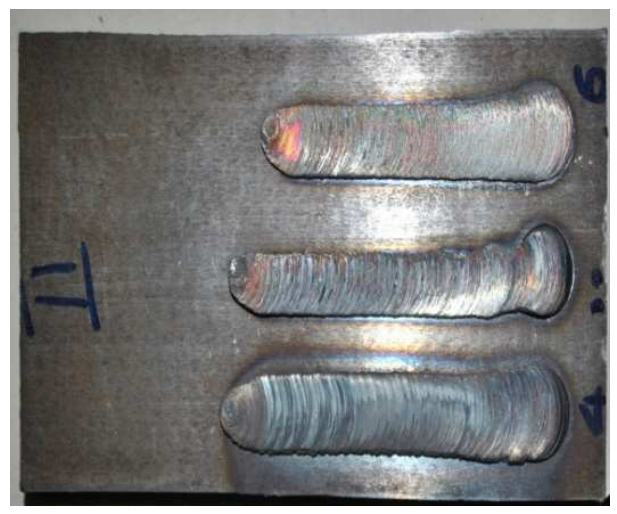

Figure 7

Deposit on III Plate (Multi Layer Deposit)

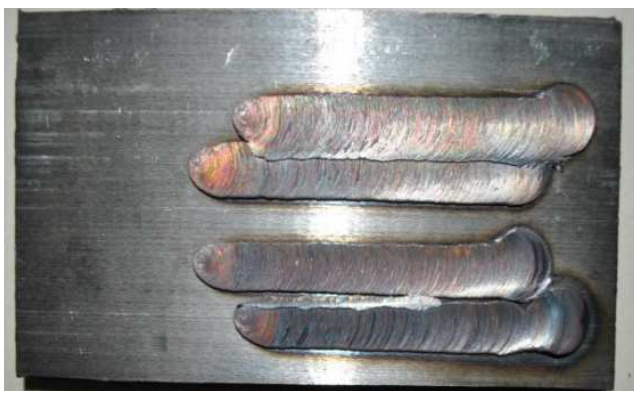

Figure 8

The figures for individual treatment combinations are shown below:

For Treatment Combination $1\left(1^{\text {st }}\right.$ Set of Parameters)

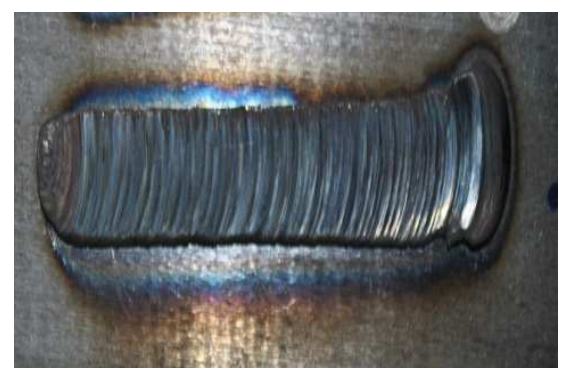

Figure 9

For Treatment Combination $2\left(2^{\text {nd }}\right.$ Set of Parameters $)$

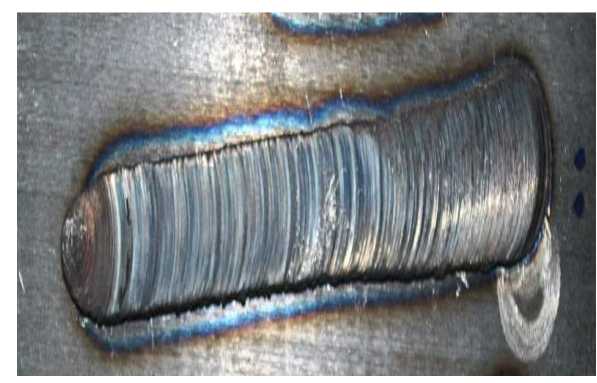

Figure 10 
For Treatment Combination $3\left(3^{\text {rd }}\right.$ Set of Parameters $)$

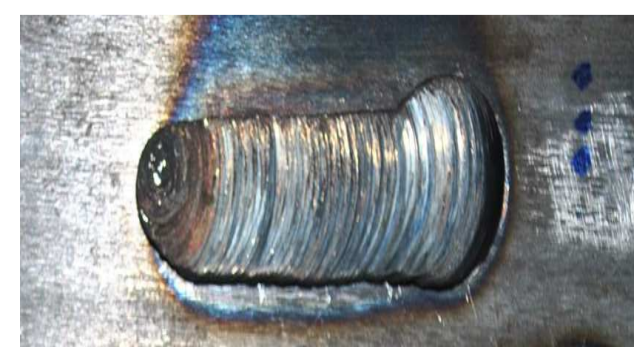

Figure 11

For Treatment Combination 4 ( $4^{\text {th }}$ Set of Parameters)

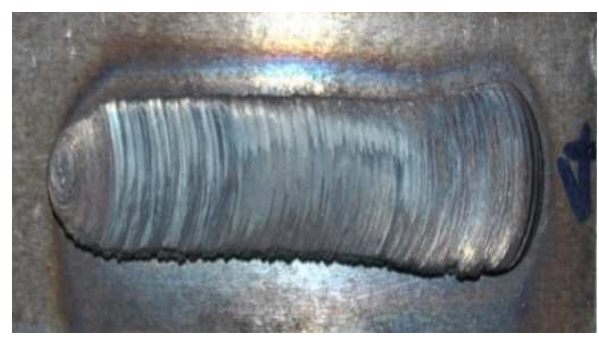

Figure 12

For Treatment Combination 5 ( $5^{\text {th }}$ Set of Parameters)

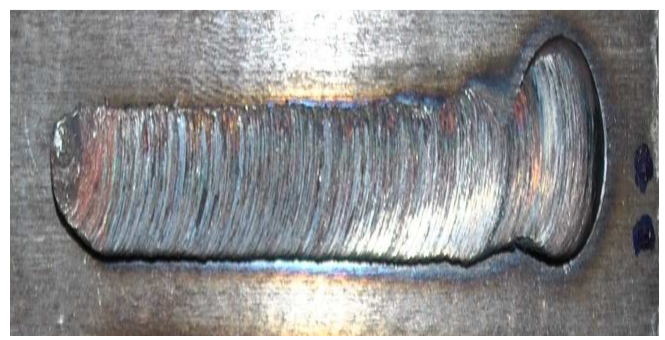

Figure 13

For Treatment Combination 6 ( $6^{\text {th }}$ Set of Parameters $)$

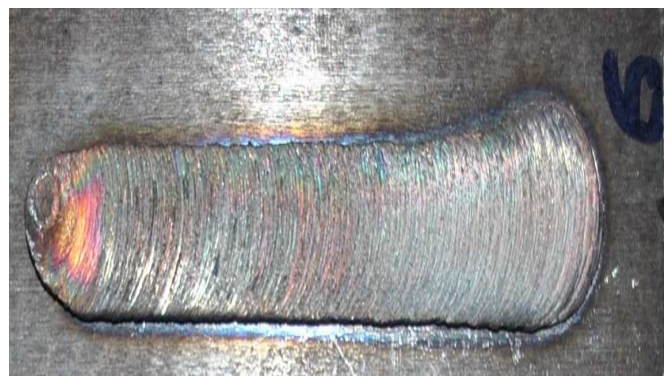

Figure 14

The figure of the stainless steel mechtrode after the deposition of one treatment combination is shown below: 


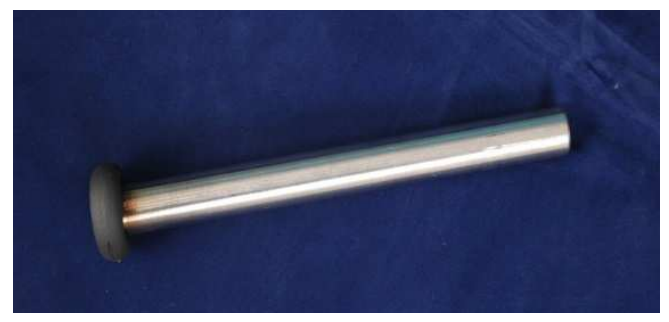

Figure 15: Formation of Quasi-Liquid Layer

During the friction surfacing process, the diameter of the material transferring zone is less than that of the coating rod, which means that the zone for material transferring is limited to the central zone and not the end surface of the coating rod. This transferring zone is named as the 'real rotational contact zone' through the real rotational contact plane, the coating materials transfer from the end of the coating rod to the substrate to form the coating layer, during which violent rubbing and torsion occurs for a short time. The microstructure of the material at the bottom end of the coating rod changes and quasi-liquid layer forms which then transfers downwards, with a decrease in temperature, the material's viscosity increases and its plasticity decreases simultaneously, after which the new quasi-liquid layer emerges. In the present study, the quasi-liquid layer is treated as the liquid with special quality in that, it is not completely composed of the liquid state material, but of the viscous flowing material of special performance. This means that, it consists of part liquid and part solid and it behaves between pure liquid and pure solid. It is then treated as solid after it transfers to the substrate. Meanwhile, the real rotational contact zone, which has the highest temperature in the whole system, is regarded as the heat source. On the real rotational contact plane, the quasi- liquid layer forms and then continuously transforms to solid.

\section{TESTING THE BOND}

NDT techniques are used for evaluation of quality of friction surfaced deposits. Visual inspection is performed and found that, they obtained deposit is free from voids, pores and surface cracks. Adhesion tests like lifting, chiseling and hammering, and grinding wheel tests are conducted. It is observed that, surface finish obtained is not uniform for all the deposits. Moreover, the width and thickness of the deposit is not uniform throughout, the entire length. It is observed that, the thickness and width are more at starting position of the deposit and decreased suddenly. Then the remaining length is having approximately uniform value.

Measurements of the bonded material

Width of the Deposit: Digital vernier calliper is used to measure the width of the deposit and the least count of the instrument is 0.01. Clean the surfaces of the bead and mark eight points, with a scriber along the length of the deposit carefully at eight positions. Measure the width of deposit at marked positions and take the average of those. This average value will be taken as the width of bead. Repeat the same for the remaining deposits and the values are tabulated.

Height of the Deposit: The height of the deposit is measured with dial indicator, having the least count $0.01 \mathrm{~mm}$. Substrate plate is cleaned thoroughly, on both sides and placed on a plane surface with deposit on upper side. Mark eight points with a scriber along the length of the deposit carefully, at eight positions. Measure the height of the deposit at three positions, along the width of the deposit near the marked point and determine its average. Complete the same procedure at the remaining seven marked points. Now, take the mean of those averages. This value will be taken as the height of the deposit, for that treatment combination. Repeat the same for the remaining deposits and the values are tabulated. 
Surface Roughness of the Deposit: Surface roughness is measured with surface roughness tester, made by Tsusubushi Corporation, Japan. The selected sample length is $0.8 \mathrm{~mm}$ and the substrate is placed over a plane surface. Measure the surface roughness at three positions, along the length of the deposit and calculate the mean value. This value will be taken as the surface roughness value, for that treatment combination. Repeat the same for the remaining deposits and the values are tabulated.

Table 3: Measurements of the Bonded Material

\begin{tabular}{|c|c|c|c|}
\hline $\begin{array}{c}\text { Treatment } \\
\text { Combination }\end{array}$ & $\begin{array}{c}\text { Width of the } \\
\text { Deposit }(\mathbf{m m})\end{array}$ & $\begin{array}{c}\text { Height of the } \\
\text { Deposit }(\mathbf{m m})\end{array}$ & Surface Roughness $(\boldsymbol{\mu})$ \\
\hline 1 & 11.2 & 1.56 & 6.86 \\
\hline 2 & 12.7 & 2.71 & 2.84 \\
\hline 3 & 11.81 & 1.41 & 6.05 \\
\hline 4 & 14.18 & 1.72 & 1.74 \\
\hline 5 & 10.43 & 1.04 & 6.1 \\
\hline 6 & 12.35 & 1.11 & 7.73 \\
\hline 7 & 10.68 & 0.81 & 6.75 \\
\hline 8 & 13.24 & 1.42 & 9.68 \\
\hline
\end{tabular}

\section{Testing for Shear Strength and Tensile Strength}

\section{Shear Strength Sample Preparation and Testing:}

The substrate plates are cut into pieces of $25 \mathrm{~mm}$ length and the width of the deposits are milled to obtain $4 \mathrm{~mm}$ of width. The edges of the deposit are perpendicular to the edges of the specimen, so that the shearing area (4 $\mathrm{x} 25 \mathrm{~mm} 2)$ for each sample is constant. The figures of the samples prepared for each treatment combination are shown below:

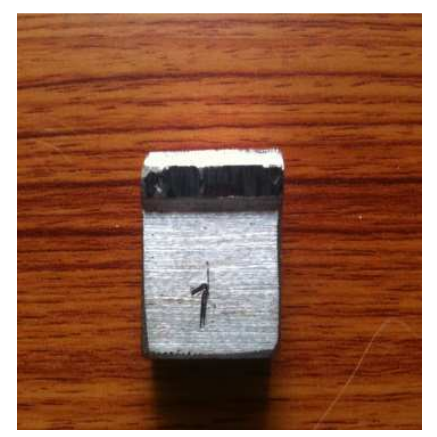

Figure 16: For Treatment Combination 1 Sample

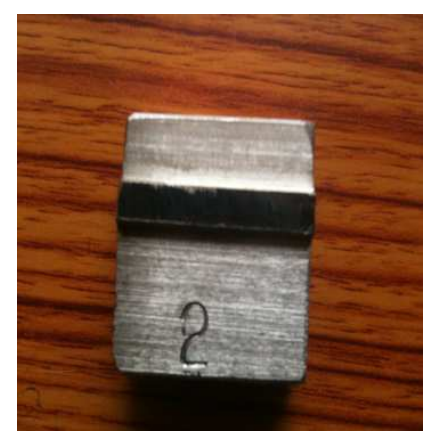

Figure 17: For Treatment Combination 2 Sample 


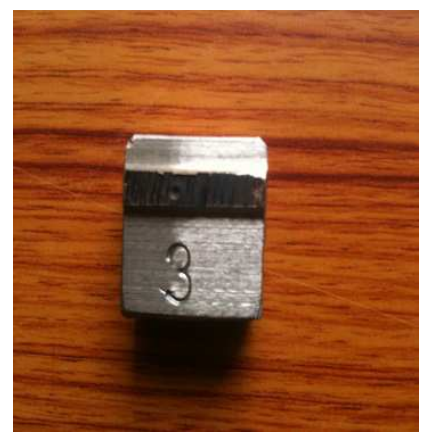

Figure 18: For Treatment Combination 3 Sample

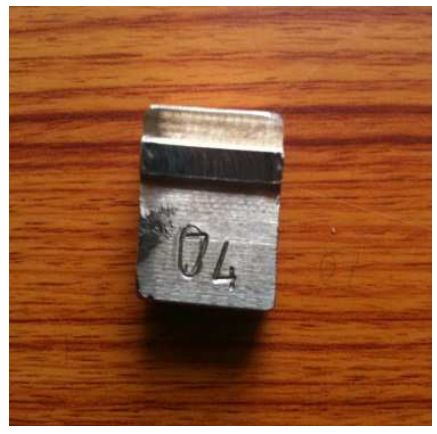

Figure 19: For Treatment Combination 4 Sample

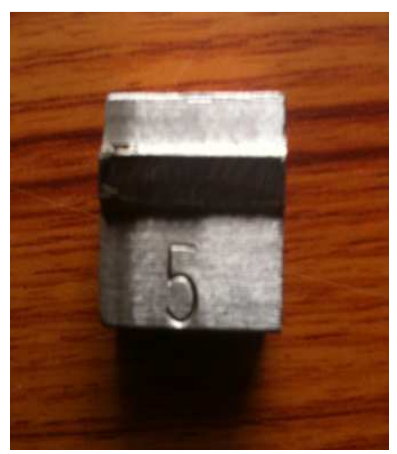

Figure 20: For Treatment Combination 5 Sample

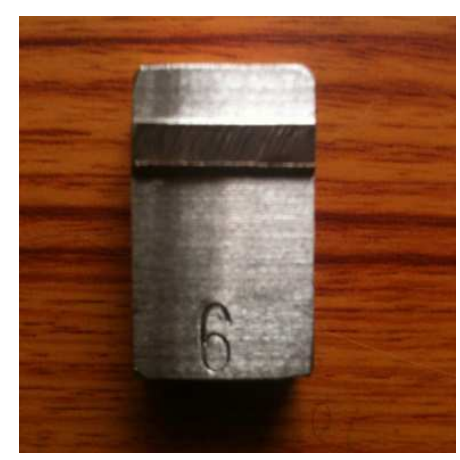

Figure 21: For Treatment Combination 6 Sample 


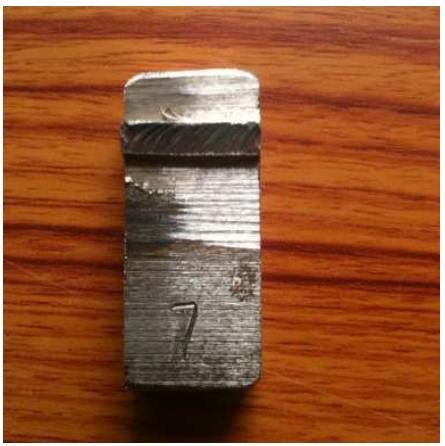

Figure 22: For Treatment Combination 7 Sample

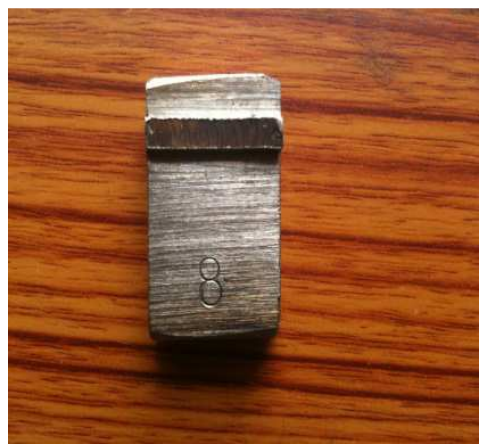

Figure 23: For Treatment Combination 8 Sample

A 40 Ton Universal Testing Machine is used for determining the shear strength of the bond deposited. The least count of the machine is $0.5 \mathrm{KN}$.

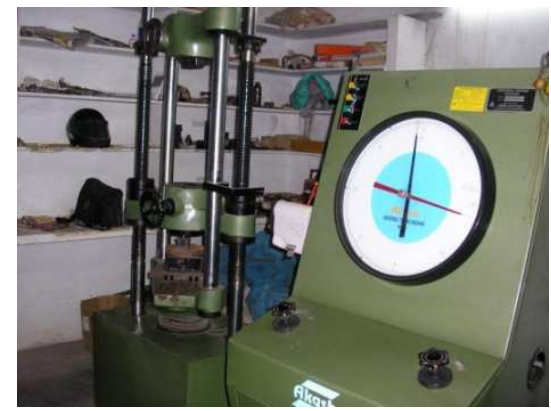

Figure 24: 40 Ton UTM Machine

A special fixture was designed and manufactured, for holding the sample under the ram of the machine. The figure of the fixture is shown below:

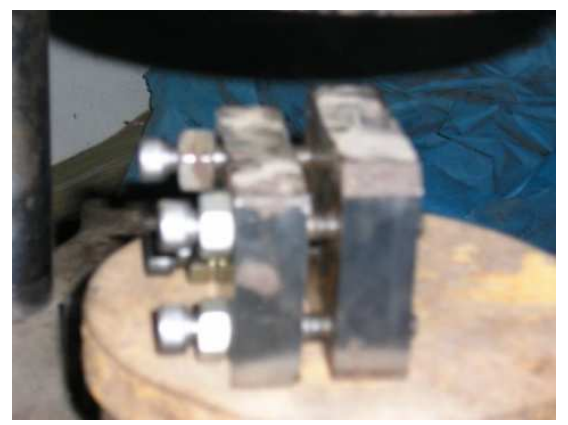

Figure 25: Fixture for Holding the Sample for Shear Test 
The specimen is kept in the fixture such that, bearing surface is parallel to the edge of the surface on which load is applied. The figure of the placement of the fixture, along with the sample on the machine bed is shown below:

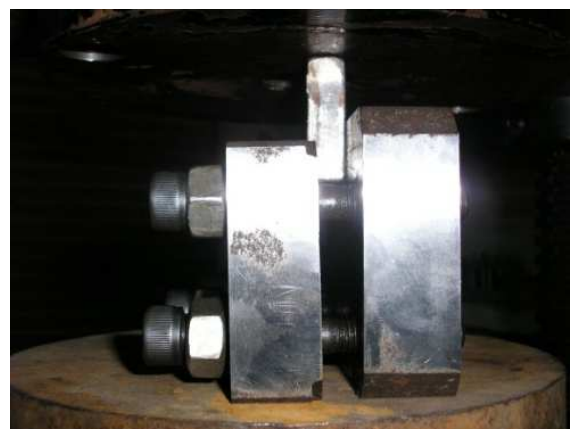

Figure 26: Sample Placed in the Fixture while the Operation

On applying load on the specimen gradually, at certain position the deposit is detached from the substrate. Take the reading of the load indicator pointer. The shear strength is obtained by the ratio of load applied to contact area. The process was repeated for the remaining deposits and the values for the shear strength of the bond are tabulated.

Table 4: Shear Strength Values for Each Sample

\begin{tabular}{|c|c|}
\hline $\begin{array}{c}\text { Treatment } \\
\text { Combination }\end{array}$ & $\begin{array}{c}\text { Shear strength } \\
\mathbf{K g} / \mathbf{m m}^{2}\end{array}$ \\
\hline 1 & 7.4 \\
\hline 2 & 8.26 \\
\hline 3 & 7.55 \\
\hline 4 & 16.12 \\
\hline 5 & 16.12 \\
\hline 6 & 18.16 \\
\hline 7 & 16.83 \\
\hline 8 & 36.22 \\
\hline
\end{tabular}

Table 5: Tensile Strength Values for Each Sample

\begin{tabular}{|c|c|}
\hline $\begin{array}{c}\text { Treatment } \\
\text { Combination }\end{array}$ & $\begin{array}{c}\text { Tensile strength } \\
\mathbf{K g} / \mathbf{m m}^{\mathbf{2}}\end{array}$ \\
\hline 1 & 31.35 \\
\hline 2 & 43.09 \\
\hline 3 & 66.48 \\
\hline 4 & 46.78 \\
\hline 5 & 51.93 \\
\hline 6 & 48.41 \\
\hline 7 & 30.79 \\
\hline 8 & 37.77 \\
\hline
\end{tabular}

Table 6

\begin{tabular}{|c|l|c|c|c|c|c|c|c|}
\hline S. No. & T.C. & $\begin{array}{c}\text { Responses } \\
(\mathbf{y})\end{array}$ & Column1 & Column2 & $\begin{array}{c}\text { Column3 } \\
(\mathbf{z})\end{array}$ & $\begin{array}{c}\text { TSS } \\
(\mathbf{z} / 8)\end{array}$ & $\begin{array}{c}\text { F Ratio } \\
(\mathbf{T S S} / \mathbf{M S S})\end{array}$ & $\begin{array}{c}\text { Significant } \\
\text { Factors(z/8), } \\
(\boldsymbol{\beta} \text { coef.'s) }\end{array}$ \\
\hline 1 & 1 & 7.4 & 15.66 & 39.33 & 126.67 & 2005.66 & 1.0001 & - \\
\hline 2 & $\mathrm{X}_{1}$ & 8.26 & 23.67 & 87.34 & 30.86 & 119.04 & $0.059 * * *$ & $3.86,\left(\beta_{1}\right)$ \\
\hline 3 & $\mathrm{X}_{2}$ & 7.55 & 34.28 & 9.43 & 26.79 & 89.71 & $0.044 * *$ & $3.34,\left(\beta_{2}\right)$ \\
\hline 4 & $\mathrm{X}_{1} \mathrm{X}_{2}$ & 16.12 & 53.06 & 21.43 & 25.06 & 78.5 & $0.039 *$ & $3.13,\left(\beta_{12}\right)$ \\
\hline 5 & $\mathrm{X}_{3}$ & 16.12 & 0.86 & 8.01 & 48.01 & 288.12 & $0.143 * * *$ & $6.0,\left(\beta_{3}\right)$ \\
\hline 6 & $\mathrm{X}_{1} \mathrm{X}_{3}$ & 18.16 & 8.57 & 18.78 & 12.0 & 18 & 0.009 & $1.5,\left(\beta_{13}\right)$ \\
\hline 7 & $\mathrm{X}_{2} \mathrm{X}_{3}$ & 16.83 & 2.04 & 7.71 & 10.77 & 14.5 & 0.0072 & $1.35,\left(\beta_{23}\right)$ \\
\hline 8 & $\mathrm{X}_{1} \mathrm{X}_{2} \mathrm{X}_{3}$ & 36.22 & 19.39 & 17.35 & 9.64 & 11.61 & 0.0057 & $1.2,\left(\beta_{123}\right)$ \\
\hline
\end{tabular}




\section{ANALYSIS USING REGRESSION EQUATION}

Mean Sum of Squares, MSS $=(\text { sum of responses })^{2} / 8=(126.66)^{2} / 8=2005.34445$

TSS- Total Sum of Squares

T.C. - Treatment Combinations

Average of the responses, $\mathrm{y}_{0}=15.8325$

Standard deviation $=9.41$

General Regression equation is,

$\mathbf{y}=\mathbf{y}_{0}+\beta_{1} X_{1}+\beta_{2} X_{2}+\beta_{3} X_{3}+\beta_{12} X_{1} X_{2}+\beta_{13} X_{1} X_{3}+\beta_{23} X_{2} X_{3}+\beta_{123} X_{1} X_{2} X_{3}$

Now, eliminating the least important terms, the equation can be written as,

$\mathrm{y}=15.8325+3.86 \mathrm{X}_{1}+3.34 \mathrm{X}_{2}+3.13 \mathrm{X}_{1} \mathrm{X}_{2}+6.0 \mathrm{X}_{3}$

From above equation we can conclude that for optimum shear strength characteristics of the bonded material, force (i.e., pressure applied) should be more, and speed (i.e., rpm) should be more, and traverse speed should be more, also the combination of force and rpm should be more.

\section{For Tensile Strength}

Table 7

\begin{tabular}{|c|l|c|c|c|c|c|c|c|}
\hline $\begin{array}{c}\text { S. } \\
\text { No. }\end{array}$ & T.C. & $\begin{array}{c}\text { Responses } \\
(\mathbf{y})\end{array}$ & Column1 & Column2 & $\begin{array}{c}\text { Column3 } \\
(\mathbf{z})\end{array}$ & $\begin{array}{c}\text { TSS } \\
\left(\mathbf{z}^{2} / 8\right)\end{array}$ & $\begin{array}{c}\text { F Ratio } \\
(\mathbf{T S S} / \mathrm{MSS})\end{array}$ & $\begin{array}{c}\text { Significant } \\
\text { Factors(z/8), } \\
(\boldsymbol{\beta} \text { coef.'s })\end{array}$ \\
\hline 1 & 1 & 31.35 & 74.44 & 187.7 & 356.6 & 15895.445 & 1 & - \\
\hline 2 & $\mathrm{X}_{1}$ & 43.09 & 113.26 & 168.9 & -4.5 & 2.53 & 0.000159 & $-0.5625,\left(\beta_{1}\right)$ \\
\hline 3 & $\mathrm{X}_{2}$ & 66.48 & 100.34 & -7.96 & 7.04 & 6.19 & 0.000389 & $0.88,\left(\beta_{2}\right)$ \\
\hline 4 & $\mathrm{X}_{1} \mathrm{X}_{2}$ & 46.78 & 68.56 & 3.46 & -20.94 & 54.81 & $0.00344 * * *$ & $-2.6175,\left(\beta_{12}\right)$ \\
\hline 5 & $\mathrm{X}_{3}$ & 51.93 & 11.74 & 38.82 & -18.8 & 44.18 & $0.00277 * *$ & $-2.35,\left(\beta_{3}\right)$ \\
\hline 6 & $\mathrm{X}_{1} \mathrm{X}_{3}$ & 48.41 & -19.7 & -31.78 & 11.42 & 16.30 & $0.00102 *$ & $1.42,\left(\beta_{13}\right)$ \\
\hline 7 & $\mathrm{X}_{2} \mathrm{X}_{3}$ & 30.79 & -3.52 & -31.44 & -70.6 & 623.04 & $0.0391 * * * * *$ & $-8.825,\left(\beta_{23}\right)$ \\
\hline 8 & $\mathrm{X}_{1} \mathrm{X}_{2} \mathrm{X}_{3}$ & 37.77 & 6.98 & 10.5 & 41.94 & 219.87 & $0.01383 * * * *$ & $5.2425,\left(\beta_{123}\right)$ \\
\hline
\end{tabular}

Mean Sum of Squares, MSS $=(\text { sum of responses })^{2} / 8=(356.6)^{2} / 8=15895.445$

TSS- Total Sum of Squares

T.C. - Treatment Combinations

Average of the responses, $\mathrm{y}_{0}=44.575$

Standard deviation $=11.75$

General Regression equation is,

$y=y_{0}+\beta_{1} X_{1}+\beta_{2} X_{2}+\beta_{3} X_{3}+\beta_{12} X_{1} X_{2}+\beta_{13} X_{1} X_{3}+\beta_{23} X_{2} X_{3}+\beta_{123} X_{1} X_{2} X_{3}$

Now, eliminating the least important terms, the equation can be written as,

$y=44.575-2.35 X_{3}-2.6175 X_{1} X_{2}+1.42 X_{1} X_{3}-8.825 X_{2} X_{3}+5.2425 X_{1} X_{2} X_{3}$ 
From above equation we can conclude that, for optimum tensile strength, characteristics of the bonded material, feed (welding speed) should be less, the combination of force and speed should be less, the combination of force and feed should be more, the combination of speed and feed should be less, and the combination of force, speed and feed should be more.

\section{For Height of the Deposit}

Table 8

\begin{tabular}{|c|l|c|c|c|c|c|c|l|}
\hline $\begin{array}{c}\text { S. } \\
\text { No. }\end{array}$ & T.C. & $\begin{array}{c}\text { Responses } \\
(\mathbf{y})\end{array}$ & Column1 & Column2 & $\begin{array}{c}\text { Column3 } \\
(\mathbf{z})\end{array}$ & $\begin{array}{c}\text { TSS } \\
\left(\mathbf{z}^{2} / 8\right)\end{array}$ & $\begin{array}{c}\text { F Ratio } \\
(\mathbf{T S S} / \mathrm{MSS})\end{array}$ & $\begin{array}{c}\text { Significant } \\
\mathbf{F a c t o r s}(\mathbf{z} / \mathbf{8}) \\
(\boldsymbol{\beta} \text { coef.'s) }\end{array}$ \\
\hline 1 & 1 & 1.56 & 4.27 & 7.4 & 11.78 & 17.34 & 1 & - \\
\hline 2 & $\mathrm{X}_{1}$ & 2.71 & 1.13 & 4.38 & 2.14 & 0.57 & $0.03 * * *$ & $0.27,\left(\beta_{1}\right)$ \\
\hline 3 & $\mathrm{X}_{2}$ & 1.41 & 2.15 & 1.46 & 1.22 & 0.19 & $0.01 * *$ & $0.15,\left(\beta_{2}\right)$ \\
\hline 4 & $\mathrm{X}_{1} \mathrm{X}_{2}$ & 1.72 & 2.23 & 0.68 & -0.3 & 0.01 & 0.0006 & $-0.04,\left(\beta_{12}\right)$ \\
\hline 5 & $\mathrm{X}_{3}$ & 1.04 & 1.15 & 1.14 & -3.02 & 1.14 & $0.066^{* * * * *}$ & $-0.4,\left(\beta_{3}\right)$ \\
\hline 6 & $\mathrm{X}_{1} \mathrm{X}_{3}$ & 1.11 & 0.31 & 0.08 & -0.78 & 0.08 & $0.0046^{* * * *}$ & $-0.10,\left(\beta_{13}\right)$ \\
\hline 7 & $\mathrm{X}_{2} \mathrm{X}_{3}$ & 0.81 & 0.07 & -0.84 & -1.06 & 0.14 & 0.008 & $-0.13,\left(\beta_{23}\right)$ \\
\hline 8 & $\mathrm{X}_{1} \mathrm{X}_{2} \mathrm{X}_{3}$ & 1.42 & 0.61 & 0.54 & 1.38 & 0.22 & $0.013^{*}$ & $0.17,\left(\beta_{123}\right)$ \\
\hline
\end{tabular}

Mean Sum of Squares, MSS $=(\text { sum of responses })^{2} / 8=(11.78)^{2} / 8=17.34$

TSS- Total Sum of Squares

T.C. - Treatment Combinations

Average of the responses, $\mathrm{y}_{0}=1.4725$

Standard deviation $=0.562$

General Regression equation is,

$\mathbf{y}=\mathbf{y}_{0}+\beta_{1} X_{1}+\beta_{2} X_{2}+\beta_{3} X_{3}+\beta_{12} X_{1} X_{2}+\beta_{13} X_{1} X_{3}+\beta_{23} X_{2} X_{3}+\beta_{123} X_{1} X_{2} X_{3}$

Now, eliminating the least important terms, the equation can be written as,

$\mathrm{y}=1.4725+0.27 \mathrm{X}_{1}+0.15 \mathrm{X}_{2}-0.4 \mathrm{X}_{3}-0.10 \mathrm{X}_{1} \mathrm{X}_{3}+0.17 \mathrm{X}_{1} \mathrm{X}_{2} \mathrm{X}_{3}$

From the above equation we can conclude that, for the optimum height of the deposit, force should be more, speed should be more, feed should be less, combination of force and feed should be less, and the combination of force, speed and feed should be more.

\section{For Width of the Deposit}

Table 9

\begin{tabular}{|c|l|c|c|c|c|c|c|c|}
\hline S. No. & T.C. & $\begin{array}{c}\text { Responses } \\
(\mathbf{y})\end{array}$ & Column1 & Column2 & $\begin{array}{c}\text { Column3 } \\
(\mathbf{z})\end{array}$ & $\begin{array}{c}\text { TSS } \\
\left(\mathbf{z}^{2} / \mathbf{8}\right)\end{array}$ & $\begin{array}{c}\text { F Ratio } \\
(\mathbf{T S S} / \mathbf{M S S})\end{array}$ & $\begin{array}{c}\text { Significant } \\
\text { Factors(z/8), } \\
(\boldsymbol{\beta} \text { coef.'s) }\end{array}$ \\
\hline 1 & 1 & 11.2 & 23.9 & 49.89 & 96.59 & 1166.2 & 1.0002 & - \\
\hline 2 & $\mathrm{X}_{1}$ & 12.7 & 25.99 & 46.7 & 8.35 & 8.72 & $0.0075^{* * *}$ & $1.04,\left(\beta_{1}\right)$ \\
\hline 3 & $\mathrm{X}_{2}$ & 11.81 & 22.78 & 3.87 & 3.23 & 1.3 & $0.001^{* *}$ & $0.4,\left(\beta_{2}\right)$ \\
\hline 4 & $\mathrm{X}_{1} \mathrm{X}_{2}$ & 14.18 & 23.92 & 4.48 & 1.51 & 0.29 & $0.0002^{*}$ & $0.19,\left(\beta_{12}\right)$ \\
\hline 5 & $\mathrm{X}_{3}$ & 10.43 & 1.5 & 2.09 & -3.19 & 1.27 & $0.001^{* *}$ & $-0.4,\left(\beta_{3}\right)$ \\
\hline 6 & $\mathrm{X}_{1} \mathrm{X}_{3}$ & 12.35 & 2.37 & 1.14 & 0.61 & 0.05 & 0.00004 & $-0.076,\left(\beta_{13}\right)$ \\
\hline 7 & $\mathrm{X}_{2} \mathrm{X}_{3}$ & 10.68 & 1.92 & 0.87 & -0.95 & 0.11 & 0.00009 & $-0.12,\left(\beta_{23}\right)$ \\
\hline 8 & $\mathrm{X}_{1} \mathrm{X}_{2} \mathrm{X}_{3}$ & 13.24 & 2.56 & 0.64 & -0.23 & 0.007 & 0.000006 & $-0.03,\left(\beta_{123}\right)$ \\
\hline
\end{tabular}


Mean Sum of Squares, MSS $=(\text { sum of responses })^{2} / 8=(96.588)^{2} / 8=1165.96$

TSS- Total Sum of Squares

T.C. - Treatment Combinations

Average of the responses, $\mathrm{y}_{0}=12.07375$

Standard deviation $=1.3$

General Regression equation is,

$y=y_{0}+\beta_{1} X_{1}+\beta_{2} X_{2}+\beta_{3} X_{3}+\beta_{12} X_{1} X_{2}+\beta_{13} X_{1} X_{3}+\beta_{23} X_{2} X_{3}+\beta_{123} X_{1} X_{2} X_{3}$

Now, eliminating the least important terms, the equation can be written as,

$\mathrm{y}=12.07375+1.04 \mathrm{X}_{1}+0.4 \mathrm{X}_{2}-0.4 \mathrm{X}_{3}+0.19 \mathrm{X}_{1} \mathrm{X}_{2}$

From the above equation we can conclude that, for optimum width of the deposit, force should be more, speed should be more, feed should be less, and the combination of force and speed should be more.

\section{For Surface Roughness}

\section{Table 10}

\begin{tabular}{|l|l|c|c|c|c|c|c|c|}
\hline $\begin{array}{c}\text { S. } \\
\text { No. }\end{array}$ & T.C. & $\begin{array}{c}\text { Responses } \\
(\mathbf{y})\end{array}$ & Column1 & Column2 & $\begin{array}{c}\text { Column3 } \\
(\mathbf{z})\end{array}$ & $\begin{array}{c}\text { TSS } \\
\left(\mathbf{z}^{\mathbf{2} / 8)}\right.\end{array}$ & $\begin{array}{c}\text { F Ratio } \\
\mathbf{T S S} / \mathbf{T S S})\end{array}$ & $\begin{array}{c}\text { Significant } \\
\text { Factors(z/8), } \\
(\boldsymbol{\beta} \text { coef.'s) }\end{array}$ \\
\hline 1 & 1 & 6.86 & 9.7 & 17.49 & 47.75 & 285 & 1 & - \\
\hline 2 & $\mathrm{X}_{1}$ & 2.84 & 7.79 & 30.26 & -3.77 & 1.78 & $0.0062^{*}$ & $-0.47,\left(\beta_{1}\right)$ \\
\hline 3 & $\mathrm{X}_{2}$ & 6.05 & 13.83 & -8.33 & 0.69 & 0.06 & 0.0002 & $0.09,\left(\beta_{2}\right)$ \\
\hline 4 & $\mathrm{X}_{1} \mathrm{X}_{2}$ & 1.74 & 16.43 & 4.56 & 1.01 & 0.13 & 0.00046 & $0.126,\left(\beta_{12}\right)$ \\
\hline 5 & $\mathrm{X}_{3}$ & 6.1 & -4.02 & -1.91 & 12.77 & 20.38 & $0.072^{* * *}$ & $1.6,\left(\beta_{3}\right)$ \\
\hline 6 & $\mathrm{X}_{1} \mathrm{X}_{3}$ & 7.73 & -4.31 & 2.6 & 12.89 & 20.77 & $0.073 * * * *$ & $1.61,\left(\beta_{13}\right)$ \\
\hline 7 & $\mathrm{X}_{2} \mathrm{X}_{3}$ & 6.75 & 1.63 & -0.29 & 4.51 & 2.54 & $0.009 * *$ & $0.56,\left(\beta_{23}\right)$ \\
\hline 8 & $\mathrm{X}_{1} \mathrm{X}_{2} \mathrm{X}_{3}$ & 9.68 & 2.93 & 1.3 & 1.59 & 0.32 & 0.0011 & $0.199,\left(\beta_{123}\right)$ \\
\hline
\end{tabular}

Mean Sum of Squares, MSS $=(\text { sum of responses })^{2} / 8=(47.75)^{2} / 8=285$

TSS- Total Sum of Squares

T.C. - Treatment Combinations

Average of the responses, $\mathrm{y}_{0}=5.96875$

Standard deviation $=2.57$

General Regression equation is,

$y=y_{0}+\beta_{1} X_{1}+\beta_{2} X_{2}+\beta_{3} X_{3}+\beta_{12} X_{1} X_{2}+\beta_{13} X_{1} X_{3}+\beta_{23} X_{2} X_{3}+\beta_{123} X_{1} X_{2} X_{3}$

Now, eliminating the least important terms, the equation can be written as,

$y=5.96875-0.47 X_{1}+1.6 X_{3}+1.61 X_{1} X_{3}+0.56 X_{2} X_{3}$

From the above equation we can conclude that, for optimum surface roughness, the force should be less, feed 
should be more, the combination of force and feed should be more, and the combination of speed and feed should be more

\section{RESULTS DISCUSSION AND CONCLUSIONS}

When the rotating mechtrode touches the substrate, it gives huge sound and machine gets vibrations. This is decreased while material is depositing. The coating thickness and width is more, when the substrate is stationary than moving. Probably, because of dry friction present in between mating parts, more heat is generated and after some time the upper layer gets plasticized and act as lubricating film and hence, coefficient of friction is decreased that lowers the generation of heat. To compensate this loss of heat suitable parameters are important for that combination. At the end of the deposit some portion of the deposited material is lifted, while mechtrode moves up and it is the process disadvantage and hence, while taking the length deposit, compensates these values. The coating width is always lesser than diameter (D) of the mechtrode. It lies in between 2/3D to 3/4D and its value depends on process parameters. Hence, while depositing in slots and recess, the diameter of mechtrode should be more than the width of the slots, but lack of bonding observed at the outer edges of the deposit. From the regression equation it was found that, the width of the deposit obtained is proportional to the friction force, speed of the mechtrode, combination of force and speed, and is inversely proportional to traverse speed. But there is limitation in increase of the frictional pressure that may bend the mechtrode at forging temperature. Graphically it can be depicted as:

The height of the coating deposit is proportional to friction pressure, rotational speed, combination of all the three parameters, and is inversely proportional to traverse speed, combination of friction force and traverse speed. The mechtrode speed is only useful for generation of heat but does not have effect on height of the deposit. Graphically it can be depicted as:

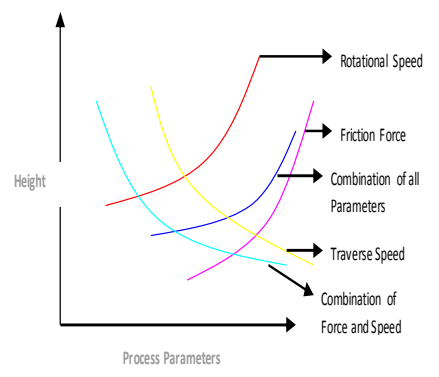

Figure 28

Surface roughness of the deposit is proportional to traverse speed, combination of friction force and traverse speed, combination of rotational speed and traverse speed, and is indirectly proportional to friction force graphically it can be depicted as:

Shear strength of the deposit is proportional to all the three process parameters and the combination of friction force and rotational speed. Graphically it can be depicted as: 


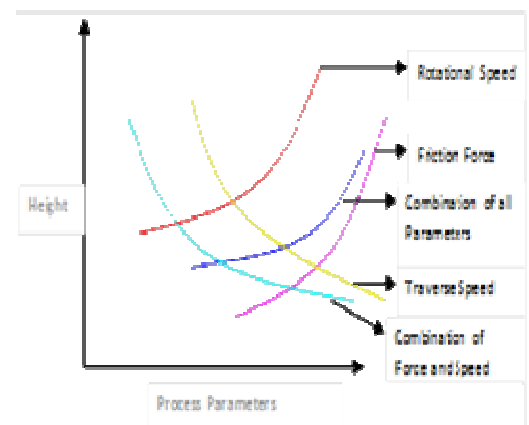

Figure 29

Tensile strength of the deposit is proportional to combination of friction force and traverse speed, combination of all the three process parameters, and is inversely proportional to traverse speed, combination of friction force and rotational speed, combination of rotational speed and traverse speed. Graphically it can be depicted as:

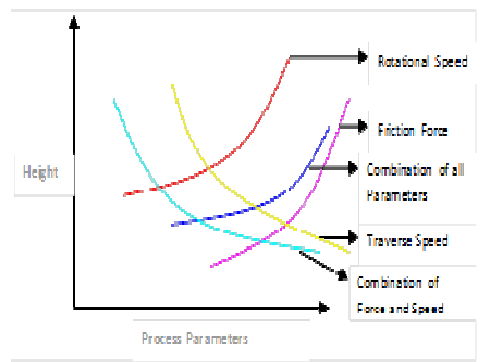

Figure 30

From above discussions it is concluded that, with increase in the values of frictional pressure, the values of width, height, surface finish and shear strength values increases. It doesn't have any effect on the tensile strength. But upper level of the frictional pressure depends on the forging pressure. If its value increases beyond this value there are chances of mechtrode bending while processing. With increase in the values of rotational speed, width and shear strength of the deposit increases and it doesn't have any effect on the remaining responses. With increase in traverse speed, only the shearing strength of the deposit increases but the values of all the remaining responses decreases.

There is limitation to increase in the frictional pressure and rotational speed because huge power is consumed at initial stage and also it gives huge vibrations.

The selection of process parameters mainly depends on suitability of their applications in engineering field. For example:

- Corrosion resistance: The base material has to cover the entire area but strength doesn't play any role. Hence high values of frictional pressure and mechtrode speed are required.

- $\quad$ Repairing of slots and of worm shafts: Width, Height and strength responses play important role in repairing and should have considerable strength and hence upper values of process parameters are required.

- Depositing hard facing of cutting edge: Strength.width and height responses are important for depositing hard facing of cutting edge on knives of various categories, punch, die and blades required for food processing, chemical and medical industries. Hence Frictional pressure, rotational speed and traverse speed plays important role to increase the shear strength, height and width of the deposit. 


\section{CONCLUSIONS}

Friction surfacing is an alternate method, for obtaining coatings of dissimilar materials and their selection depends on specific applications. This process is most suitable to the materials particularly, which are having low thermal conductivity. Desired properties of stainless steel deposits on low carbon steel substrate could be achieved, through closer control of process parameters with a good coating integrity and adhesion. It is possible to the friction surface directly, onto rough surfaces in open air, without surface preparation and provision of shield gas. After processing heat treatments are not required. A trained machinist is required to operate this special purpose machine.

At initial stage huge power is consumed, because of the selection of higher values for parameters. It is important, otherwise it stalls the motor running and also the machine gives huge vibrations. Suitable holding fixture is required to avoid unnecessary running problems. Large quantity of mechtrode is wasted and takes lot of time for each treatment combinations and to remove the deformed material /bulb from the mechtrode, also special equipment is required for removing it. Process takes lot of time between each trial for machine settings.

\section{REFERENCES}

1. Dr. K. G. K. Murti, Ashok Kumar A. N. Dwarakan "Exploiting Friction welding for Improved Productivity" From WRI Journal Volume 15, No.3

2. ARITOSHI, K. OKITA: “Friction Welding of Dissimilar metals” From Welding Journal 2003, 17(4) 271-275

3. M. Chandrasekharan, A. W. Batchelor, S. Jana, "Study of Interfacial Phenomenon during Friction Surfacing of Aluminum with Steels”, from Journal of Materials Science, 32(1997) page no 6055-6062.

4. H. Ochi, K. Ogawa, Y. Yamamoto, Y. Soga "Friction Welding of Al Alloys and steel" From International Journal of Offshore and Polar Engineering. Volume 8, No.2 June1998.

5. Horoshi. TOKISUE, Kaazuyoshi KATOH, Toshikatsu ASHAINA and Toshio USHIYAMA "Structural and Mechanical Properties of Multilayer Friction surfaced AL Alloys” From Industrial Technology Nihon University Nov 78, 2005

6. M.Chandrasekharan, A.W.Batchelor, S.Jana, "Study of Interfacial Phenomenon during Friction Surfacing of Mild Steel with Tool Steel and Inconel”, from Journal of Materials Science, 33(1998) page no 2709-2717.

7. G. Madhusudan Reddy, K. SrinivasraoT.Mohandas.. "Friction surfacing : "Novel technique for metal matrix composite Coating on Al. Silicon Alloys" From 2008Institute of Material, Minerals and Mining Published maney on Behalf of the Institute Received 12 Feb 2008, Accepted 25 March 2008.D01 10.1179/174329408 x298238

8. N. Rajamanickam, V. Balaswamy, G. Madhusudan Reddy and K. Natarajan "Effect of Process parameters on thermal History and mechanical properties of friction stir welds” From Science Direct "Material and Design”30 (2009) 2726-2731

9. Yoshihiro YAMASHITA AND Kazuniro FUJITA "Newly developed Repairs on Welded area of LWR Stainless steel by friction surfacing” From Journal of Nuclear Science and Technology, Volume 38, No.10, p896-900 (Oct. 2001 
